\title{
Multi-Scenarios Dynamic Matching Algorithm for Hierarchical Treatment System
}

\author{
Min Zhou ${ }^{1,2}$, Lindu Zhao ${ }^{2}$, Shujuan Qu ${ }^{3, ~}$, Kathryn Sarah Campy ${ }^{4}$ \\ ${ }^{1}$ School of Business Administration, Hunan University of Commerce, Changsha, China \\ ${ }^{2}$ School of Economics and Management, Southeast University, Nanjing, China \\ ${ }^{3}$ The Third Xiangya Hospital of Central South University, Changsha, China \\ ${ }^{4}$ Center for Public Health Initiatives, University of Pennsylvania, Philadelphia, USA
}

\section{Email address:}

zhouminlaoshi@163.com(Min Zhou),1dzhao@seu.edu.cn(Lindu Zhao), qushujuan@yahoo.com(Shujuan Qu), kscampypenn88@yahoo.com(K. S. Campy)

*Corresponding author

\section{To cite this article:}

Min Zhou, Lindu Zhao, Shujuan Qu, Kathryn Sarah Campy. Multi-Scenarios Dynamic Matching Algorithm for Hierarchical Treatment System. International Journal of Biomedical Engineering and Clinical Science. Vol. 4, No. 2, 2018, pp. 36-47. doi: 10.11648/j.ijbecs.20180402.12

Received: March 7, 2018; Accepted: March 27, 2018; Published: April 18, 2018

\begin{abstract}
In China, $10 \%$ of medical resource are general hospital which treat $86 \%$ patients. This will lead the health resources in these hospitals become insufficient and exhaust, even if the resources in other hospitals idle. Previous studies have indicated that the scattering resource systems will result in significant imbalances if it lacks stable and effective match. To deal with Two-Sided Matching (TSM) problem in hierarchical medical system, a matching decision-making approach based on multiple scenarios was proposed. The algorithm was designed to adapt four kinds of scenarios, it analyzed multi-context matching satisfaction degree of these cooperation situations in different forms of environment respectively and specifically. By comparing the examples, the multi - scenario dynamic matching method is superior to the random matching algorithm and the " $\mathrm{F}-\mathrm{Y}$ " algorithm (improved G - S algorithm), and it is effective to obtain the stable and feasible solution. This paper showed a multi-scenarios dynamic matching algorithm for hierarchical treatment system by modifying comprehensive satisfaction integration function and differential adjustment function. This paper concentrated on the stability and total satisfaction goals of system matching. This method serves as a decision-making reference for the bilateral matching encountered in the problem of "hierarchical treatment system" around the world.
\end{abstract}

Keywords: Hierarchical Medical System, Bilateral Matching, Multiple Scenarios, Medical Resources

\section{Introduction}

Medical administration departments around the world are facing increasing pressure to improve the quantity and quality of healthcare services. "Availability" of medical resources is an important aspect of social medical treatment goals, especially in rapidly urbanized countries or regions. The contradiction between supply and demand of medical resources is mainly reflected in quantity shortage and improper allocation. In response to the increasingly severe supply and demand situation of medical resources, some developed countries adopt the "three-level medical service network (UK)" and "family doctor (Japan)" and other forms of Hierarchical Treatment System (HTS) to improve the efficiency of medical resources utilization. In 2015, the Chinese government promulgated the Guiding Opinions on Promoting the Construction of the Classification and Treatment System. It aims to deepen the reform of the medical and health system, effectively allocate medical resources and promote the equalization of basic medical and health services [1].

Since its introduction around 2007, much has been written on the requirements and implications of HTS. The results show that the medical service resource market is a complex bilateral market with multiple attributes and non-affiliated platforms. The validity of the bilateral matching decision among the participating subjects is the prerequisite for the optimal allocation of medical resources [2]. However, one 
subject appears to have drawn less attention and that is the optimal allocation of medical resources under different scenarios. Exactly, previous studies take little account about the different priorities and influences of medical service resources subjects when they were participating in the cooperative game.

According to the collected data from China Government, the Chinese government has invested a lot of money (more than 3 trillion RMB, from 2009 to 2015) on health care in recent years, and it has significantly increased the supply of hospitals, doctors and other medical resources. For example, at November 2016, the total number of registered hospitals in China came up to 28751 from 19822 in 2008. The results show that the Chinese government has done most of the measures it can do, and the number of per capita medical resources is growing rapidly, the data close to moderately developed countries such as Italy, Spain, Japan and South Korea (Department of Health Statistics, 2016). However, increasing numbers of patients visiting hospitals every year (total attendance has risen at 7.8 billion in 2016 according to Chinese Health and Family Planning Development Statistical Bulletin (2017)), and evidences of some hospitals taking special actions to avoid overcrowding while other hospital's medical resources are often idle, suggests that optimal allocation of medical resources is still a high priority.

Utilization rate of all medical resources exhibit number-dependent behavior; that is, the patient arrival rate changes. The volume of patients is also likely to vary in different hospitals, but the number of medical resources supply cannot change flexibly in a short time. Under the condition that patients never made any reservations and the influence power of decision-making is variable, the patient quantity volume will becomes very large without any signs and the medical resources service capacity is insufficient, the service level of hospitals will be obviously weakened and other hospitals without the patient will become idle. The purpose is to determine the optimal match between Superior hospitals, Subordinate hospitals, and patients so as to meet the largest resource utilization and highest total system satisfaction in different scenes.

\section{Related Works}

To establish a service system with time-varying requirements is a major challenge, the traditional matching theory cannot be directly applied to this type of system as the main parameters (mainly the satisfaction matrix) are often change in dynamic and random way, so the matching system cannot get stable matching results. It has attracted a significant researches over the last two decades, and many approaches have been developed [3, 4].

The aim of the matching decision-making method is to focus on matching pricing decision and matching stability, improving the willingness and management effect of the bilateral market matching. Rochet and Tirole (2008) proposed a bilateral market matching price equilibrium condition: when fixed costs and benefits do not exist, the price structure must be satisfied: $-\frac{p^{i}-\left(c-p^{j}\right)}{p^{i}}=\frac{1}{\eta^{i}}$; when the royalty does not exist, the price structure must satisfy: $-\frac{p^{i}-\left(-b^{j}\right)}{p^{i}}=\frac{1}{\eta^{i}}$ [5]. Boudreau (2014) analyzed the four factors of bilateral market matching pricing decision: bilateral market price elasticity, network externality intensity, single attribution and multi-attribution and product differentiation [6]. Ingolfsson (2010) proposed a vertical bilateral market matching price strategy, Feldman (2008) obtained the pricing model of the bilateral market matching when the participants were unequal [7]. In the specific application areas, bilateral market matching pricing decision research has also become a hot topic, as the e-commerce platform pricing [8], renewable energy power system pricing [9], self-media social platform Pricing [10], bilateral pricing model decision in media [11].

In the stable matching scheme, the matching relationship between the matching subjects can be maintained and the efficiency of the bilateral market is improved. Many studies are designed to find the it, Ashlagi (2011) used a fixed point theory to obtain a stable match, and pointed out that the bilateral match is Knaster-Tarski fixed point problem, rather the bilateral matching is Kakutani fixed point problem [12]. Sarne and Kraus (2008) [13] found a way to improve the efficiency of the stable matching algorithm. Munro (2006) [14] proved that even if the matching subject's score and preference order are consistent with stable marriage matching problems, it is still a strong NP-hard problem.

The matching algorithms are covering a wide range, such as the linear programming model in the marriage match; Gale-Shapley algorithm to solve the problem of student enrollment matching [15-17]. The stable matching algorithm is solved by using the graph theory [18], exactly by setting the stable distribution of the irreversible utility and the transferable utility in the stable matching structure. Using the Hospital-Resident algorithm to solve the optimal stability of 1-n bilateral matching [19]. More stable matching results can be obtained based on the recursive algorithm of the Break-marring operator [20]. The improved matching decision algorithm includes the cumulative foreground theory decision algorithm [21], multi-objective optimization based on perceptual utility [22], Path-Relinking process of greedy random adaptation Algorithm [4], stakeholder preference fusion algorithm [23].

Participants of the medical resources bilateral-market, the abilities and preferences are dynamically adjusted, so the system matching is instable and to find a stable matching is very difficult. Traditional static matching models and algorithms cannot adapt to dynamic changes and meet the optimization goals. It is noteworthy that the rapid growth of medical demands and increasingly inadequate medical resources are the main reasons which leading to excessive load in hospitals. However, based on the survey data in Chinese hospitals, the matching efficiency between patients and hospitals is the main reason leading to unbalanced utilization of medical resources, then it led to excessive load of some hospitals. Optimization of medical resource matching model will significantly improve the efficiency of medical 
resources utilization. In comparison to the unrestricted increase in therapeutic resources, this is likely to be a much more cost-effective solution [24].

The paper is organized as follows. A generic patient-hospital $(\mathrm{P}-\mathrm{H})$ model is discussed in Section 3. The comprehensive satisfaction matrix calculation is explained in Section 4, especially included the multi-context of comprehensive satisfaction; and is designed the model solution and decision-making steps in Section 5. This is followed by the case study and discussions, conclusions in section $6-7$.

\section{Definitions}

In the hierarchical treatment system, medical resources can be divided into two categories: Superior hospital collection A, Subordinate hospital collection B. When the patient is ill, he first went to Subordinate Hospital B for initial treatment. If the condition cannot be healed in the Subordinate hospital B, he will go to Superior hospital A to find the appropriate referral recipient by matching the platform. Superior hospital A will determine whether to accept a referral request based on its own medical capacity and service resource constraints. If it is not acceptable, subordinate hospital B will need to select another Superior hospital A again as a referral hospital until a satisfactory match is obtained. The goal is to meet the overall satisfaction of the decision-making of the bilateral market, and obtain the global optimal stable matching scheme [25].

Superior hospital collection $A=\left\{A_{1}, A_{2}, \cdots, A_{m}\right\}, A_{i}$ is a subject in $A, I=\{1,2, \cdots, m\}, i \in I$. Subordinate hospital collection $B=\left\{B_{1}, B_{2}, \cdots, B_{n}\right\}, B_{j}$ is a subject in $B, J=$ $\{1,2, \cdots, n\}, j \in J$. The number of $B$ subjects can be accepted by $A_{i}$ is $s_{i}$, and $\sum_{i=1}^{m} s_{i}=s$, every $B_{j}$ can match only $1 A_{i}$. Without loss of general, let $2 \leq \mathrm{s} \leq \mathrm{n}$, and then build a typical 1-n matching problem, displayed in Figure 1.

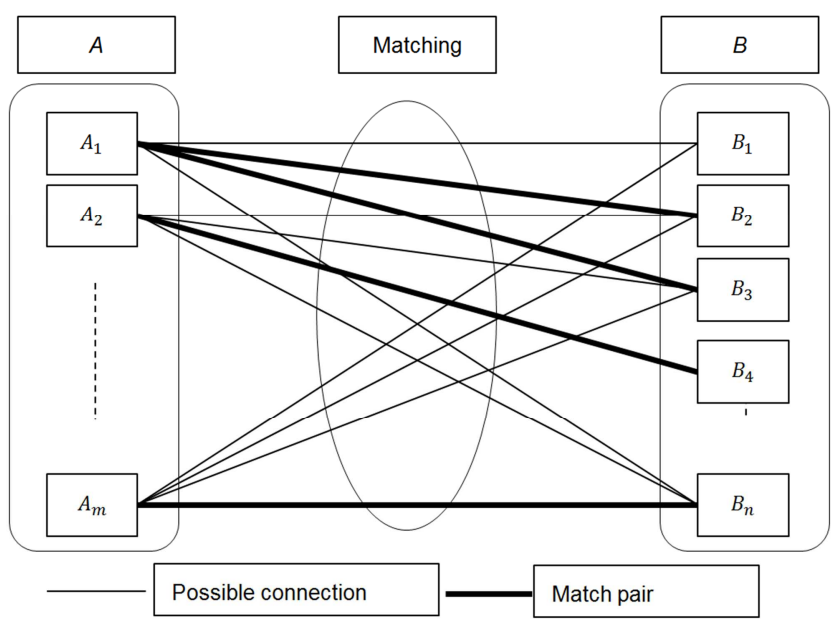

Figure 1. 1-n Bilateral Matching

$\mathrm{R}$ is the preference order matrix given by the set $\mathrm{A}$ for the main set $B, R=\left[r_{i j}\right]_{m \times n}, r_{i j}$ is the preference order given by $A_{i}$ for $B_{j}$, that is, in the order of precedence, $B_{j}$ is ranked the $r_{i j}$ in preference sequence of $A_{i}, r_{i j} \in I$. Similarly, $T$ is the preference order matrix given by the set $\mathrm{B}$ for the main set $\mathrm{A}$, $T=\left[t_{i j}\right]_{m \times n}, t_{i j}$ is the preference order given byB $B_{j}$ for $A_{i}$, $t_{i j} \in J$. In order to achieve the stable matching, Roth A E (1985) given the definition as follows [15]:

Definition 1. 1-n bilateral matching

Mapping $\quad \mu: \quad \mu$ : AUB $\rightarrow B \cup A, \forall A_{i} \in A, B_{j} \in B, \quad$ the following conditions are satisfied, the mapping is 1-n bilateral matching.

1) $\mu\left(A_{i}\right) \in B \cup\left\{A_{i}\right\}$;

2) $\mu\left(B_{j}\right) \in A \cup\left\{B_{j}\right\}$;

3) If $\mu\left(A_{i}\right)=\left\{B_{j 1}, \cdots, B_{j s_{i}}\right\}$, and $\left\{j 1, \cdots, j s_{i}\right\} \in J$, then $\mu\left(B_{j 1}\right)=A_{i}, \cdots \mu\left(B_{j s_{i}}\right)=A_{i}$;

4) If $\mu\left(B_{j}\right)=A_{i}$, then $B_{j} \in \mu\left(A_{i}\right)$;

5) $\forall \mathrm{i}, \mathrm{l} \in \mathrm{I}, \mathrm{i} \neq \mathrm{l}, \mu\left(\mathrm{A}_{\mathrm{i}}\right) \cap \mu\left(\mathrm{A}_{\mathrm{l}}\right)=\emptyset$.

Definition 2. Matching scheme

If $\mu\left(A_{i}\right)=B_{j}$, then $A_{i} \in \mu\left(B_{j}\right)$, call $\mu_{1}\left(A_{i}, B_{j}\right)$ as $\mu$-matched subject pair; if $\mu\left(B_{j}\right) \notin A$, then $\mu\left(B_{j}\right)=B_{j}, B_{j}$ did not find the appropriate $A$ to match, call $\mu_{2}\left(B_{j}, B_{j}\right)$ as the $\mu$-unmatched subject. All $\mu$-matched subject pairs and $\mu$-unmatched subjects constitute matching scheme $\theta$, $\theta=\mu_{1} \cup \mu_{2} \quad, \quad \mu_{1}=\left\{A_{i}, B_{f(i)} \mid i \in I\right\} \quad, \quad \mu_{2}=\left\{B_{j}, B_{j} \mid j \in\right.$ $J \backslash \mathrm{f}(1), \mathrm{f}(2), \ldots \mathrm{f}(\mathrm{m})\}\}, \mathrm{f}(\mathrm{i}) \in \mathrm{J}, \forall \mathrm{k}, \mathrm{l} \in \mathrm{I}, \mathrm{k} \neq \mathrm{l}, \mathrm{f}(\mathrm{k}) \neq \mathrm{f}(\mathrm{l})$.

Definition 3. Hinder matching pair

For $1-n$ bilateral matching, if the $\mu$-matched subject pair satisfies any of the following conditions, and then it is a hinder matching pair:

1) $\exists A_{i}, A_{l} \in A, B_{j}, B_{k} \in B, \mu\left(A_{i}\right)=B_{k}, \mu\left(A_{l}\right)=$ $B_{j}, r_{i j}<r_{i k}$ and $t_{i j}<t_{l j}$;

2) $\exists A_{i} \in A, B_{j}, B_{k} \in B, \mu\left(A_{i}\right)=B_{k}, \mu\left(B_{j}\right)=$ $B_{j}$, and $r_{i j}<r_{i k}$

3) $\exists A_{i}, A_{l} \in A, B_{j} \in B, \mu\left(A_{l}\right)=B_{j}, \mu\left(A_{i}\right)=A_{i}$, and $t_{i j}<t_{l j}$

4) $\exists A_{i} \in A, B_{j} \in B, \mu\left(A_{i}\right)=A_{i}, \mu\left(B_{j}\right)=B_{j}$.

Definition 4: Stable matching scheme

For 1-n bilateral matching, if hinder matching pair does not exist, then it is a stable matching scheme.

There are many differences among hospitals in facilities, service level, management mechanism, profit distribution and other aspects, and these differences are low-standardization, so evaluation value cannot be determined by quantitative methods directly. Taking into account the competition - cooperation relationship between different medical resources providers, it is a general and feasible measure to use satisfaction method to get satisfaction. In the relevant studies, the satisfaction is a mathematical transformation based on the strict preference order, provided that the preference order is strict and invariant. In the relevant studies, the strict preference order is the basis for mathematical transformation, and the preference order is strict and invariant. In addition, the difference sizes between preference values did not get attention. The method of weight determining is mainly based on qualitative analysis [13]. There is little equilibrium analysis of the preference values in different 
contexts. For all of these reasons, most of the matching results are quite different from the realities. The first problem be solved in this paper is to obtain variable comprehensive satisfaction matrix and weight matrix in multiple contexts.

\section{Model Establishment}

\subsection{Split Process}

In 1-n matching, the number of B subjects can be accepted by the subject $A_{i}$ is $s_{i}$. So $A_{i}$ can be split into $s_{i}$ virtual entities $\left\{A_{i}^{1}, A_{i}^{2}, \cdots, A_{i}^{S_{i}}\right\}$, and they have the same preference. For any virtual subject $A_{i}^{\delta_{i}}$, the number of objects can be matched is $1\left(1 \leq \delta_{i} \leq s_{i}\right)$. After transformation, A is written as $\tilde{A}$, as follows:

$$
\tilde{A}=\left\{\begin{array}{c}
{\left[A_{1}^{1}, A_{1}^{2}, \cdots, A_{1}^{s_{1}}\right]^{T} s_{1}} \\
\vdots \\
\vdots \\
{\left[A_{i}^{1}, A_{i}^{2}, \cdots, A_{i}^{s_{i}}\right]^{T} s_{i}} \\
\vdots \\
\vdots \\
{\left[A_{m}^{1}, A_{m}^{2}, \cdots, A_{m}^{s_{m}}\right]^{T} S_{m}}
\end{array}\right.
$$

$\tilde{R}$ is preference order matrix of $\tilde{A}, \tilde{R}=\left[r_{i}^{\delta_{i}}\right]_{s \times n}, r_{i}^{\delta_{i}}$ is the preference order given by $A_{i}^{\delta_{i}}$ for $\mathrm{B}_{\mathrm{j}}, 1 \leq \delta_{i} \leq s_{i}$.

$$
\begin{aligned}
& r_{i j}=r_{i_{j}}^{1}=r_{i_{j}}^{2}=, \cdots,=r_{i}^{\delta_{i}}=, \cdots,=r_{i}^{s_{i}} i \in I ; 1 \leq \delta_{i} \leq s_{i} ; j \in J \\
& t_{i j}=t_{i_{j}}^{1}=t_{i_{j}}^{2}=, \cdots,=t_{i_{j}}^{\delta_{i}}=, \cdots,=t_{i}^{s_{i}} i \in I ; 1 \leq \delta_{i} \leq s_{i} ; j \in J
\end{aligned}
$$

Based on the unilateral satisfaction formula, $\forall \mathrm{i} \in \mathrm{I}, 1 \leq$ $\delta_{\mathrm{i}} \leq \mathrm{s}_{\mathrm{i}}, \mathrm{j} \in \mathrm{J}, 0<\varepsilon \leq 1$,

$$
\begin{aligned}
& \alpha_{i_{j}}^{1}=\alpha_{i_{j}}^{2}=, \cdots,=\alpha_{i j}^{\delta_{i}}=, \cdots,=\alpha_{i_{j}}^{s_{i}}=\left(\frac{1}{r_{i j}}+\frac{1}{2 s}\right)^{\varepsilon_{A}} \\
& \beta_{i_{j}}^{1}=\beta_{i_{j}}^{2}=, \cdots,=\beta_{i_{j}}^{\delta_{i}}=, \cdots,=\beta_{i_{j}}^{s_{i}}=\left(\frac{1}{t_{i j}}+\frac{1}{2 n}\right)^{\varepsilon_{B}}
\end{aligned}
$$

The $\alpha_{i}^{\delta_{i}}$ and $\beta_{i}^{\delta_{i}}$ satisfies the following equations:

1) $0<\alpha_{i}^{\delta_{j}} \leq 1,0<\beta_{i}^{\delta_{i}} \leq 1$;

2) $\forall \mathrm{j}, \mathrm{k} \in \mathrm{J}$, if $\mathrm{r}_{\mathrm{i}}^{\delta_{\mathrm{i}}}<\mathrm{r}_{\mathrm{i}}^{\delta_{\mathrm{i}}}$, then $\alpha_{\mathrm{i}}^{\delta_{\mathrm{j}}}>\alpha_{\mathrm{i}}^{\delta_{\mathrm{i}}} ; \forall \mathrm{i} \in \mathrm{I} ; 1 \leq$ $\delta_{i} \leq s_{i}$, if $t_{i j}^{\delta_{i}}<t_{l j}$, then $\beta_{i j}^{\delta_{i}}>\beta_{l j}$.

3) Descent speed of subject satisfaction will be faster when $\varepsilon$ becomes larger.

After got the unilateral satisfaction matrix, two questions need to be considered:

First, the differences of preference value in other subject's view. When it is a very large, indicates the subject is controversial and should pay attention on it.

Second, the difference between unilateral satisfactions within each other, such as $\alpha_{i}^{\delta_{i}}$, and $\beta_{i}^{\delta_{i}}$. If $\left|\alpha_{i}^{\delta_{i}}{ }_{j}-\beta_{i}^{\delta_{i}}{ }_{j}\right|$ is

$$
\tilde{A}=\left\{\begin{array}{c}
{\left[A_{1}^{1}, A_{1}^{2}, \cdots, A_{1}^{s_{1}}\right]^{T} s_{1}} \\
\vdots \\
\vdots \\
{\left[A_{i}^{1}, A_{i}^{2}, \cdots, A_{i}^{s_{i}}\right]^{T} s_{i}} \\
\vdots \\
\vdots \\
{\left[A_{m}^{1}, A_{m}^{2}, \cdots, A_{m}^{s_{m}}\right]^{T} s_{m}}
\end{array}\right.
$$

\subsection{Unilateral Satisfaction Matrix}

Unilateral satisfaction formula as follows:

$$
\begin{aligned}
& \alpha_{i j}=\left(1 / r_{i j}\right)^{\varepsilon_{A}}, i \in I ; j \in J \\
& \beta_{i j}=\left(1 / t_{i j}\right)^{\varepsilon_{B}}, i \in I ; j \in J
\end{aligned}
$$

In order to prevent the occurrence of 0 elements, the modified unilateral satisfaction formula is as follows:

$$
\begin{gathered}
\alpha_{i j}=\left(\frac{1}{r_{i j}}+\frac{1}{2 m}\right)^{\varepsilon_{A}}, i \in I ; j \in J \\
\beta_{i j}=\left(\frac{1}{t_{i j}}+\frac{1}{2 n}\right)^{\varepsilon_{B}}, i \in I ; j \in J
\end{gathered}
$$

According to the split process of $A_{i}$ described above: very large, that will indicate the difference between mutual recognition is great. If these two subjects compose a matching pairs, it will easy have a "unilateral psychological gap" and weaken the stability of matching. This paper use weights to solve these two problems.

\subsection{Influence Weight}

According to the definition of the average information "entropy" by Shannon's Theorem, the satisfaction coefficient of the same subject (such as $A_{i}^{\delta_{i}}$ ) in other subjects (such as $B_{j}$ ) can determine Influence weight.

Step 1. Calculate the satisfaction of entropy.

Calculate the specific gravity $p_{i}^{\delta_{i}}, \forall i \in I ; 1 \leq \delta_{i} \leq s_{i}$,

$$
p_{i \beta}^{\delta_{i}}=\frac{\beta_{i}^{\delta_{i}}{ }_{j}}{\sum_{j=1}^{n} \beta_{i}^{\delta_{i}}{ }_{j}}, \beta_{i_{j}}^{\delta_{i}}>0, \sum_{j=1}^{n} \beta_{i}^{\delta_{i}}>0
$$

Get the entropy of preference sequence $e_{i}^{\delta_{i}}$.

$$
e_{i \beta}^{\delta_{i}}=-k \sum_{j=1}^{n} p_{i j \beta}^{\delta_{i}} \ln \left(p_{i j \beta}^{\delta_{i}}\right)
$$

If $\forall j \in J, p_{i \beta}^{\delta_{i}}=1 / n$, then it's information will be 
minimum, and the "entropy" will reach the maximum 1. It can be seen, $k=\frac{1}{\ln n}$, and get the following equals:

$$
e_{i \beta}^{\delta_{i}}=-\frac{1}{\ln n} \sum_{j=1}^{n} p_{i j \beta}^{\delta_{i}} \ln \left(p_{i j \beta}^{\delta_{i}}\right)
$$

As the same way, can get $e_{j \alpha}$.

$$
e_{j \alpha}=-\frac{1}{\ln s} \sum_{i=1}^{m} \sum_{\delta_{i}=1}^{S_{i}} p_{i}^{\delta_{i}} \ln \left(p_{i}^{\delta_{i}}{ }_{j \alpha}\right)
$$

Step 2. Calculate the difference coefficient

$\forall \mathrm{i} \in \mathrm{I}, 1 \leq \delta_{\mathrm{i}} \leq \mathrm{s}_{\mathrm{i}}, \mathrm{j} \in \mathrm{J}, \mathrm{e}_{\mathrm{i}}^{\delta_{\mathrm{i}}}$ can represent its rarity and information content. Then use difference coefficient to express this.

$$
\mathrm{g}_{\mathrm{j} \alpha}=1-\mathrm{e}_{\mathrm{j} \alpha}, \mathrm{g}_{\mathrm{i}}^{\delta_{\mathrm{i}}}=1-\mathrm{e}_{\mathrm{i}{ }_{\beta}}^{\delta_{\mathrm{i}}}, \mathrm{i} \in \mathrm{I} ; 1 \leq \delta_{\mathrm{i}} \leq \mathrm{s}_{\mathrm{i}} ; \mathrm{j} \in \mathrm{J} ;
$$

Step 3. Calculate the influence weight

Normalization of the difference coefficient, then get the influence weight.

$$
\begin{gathered}
w_{i}^{\delta_{i}}=\frac{g_{i}^{\delta_{i}}}{\sum_{i=1}^{m} \sum_{\delta_{i}=1}^{s_{i}} g_{i}^{\delta_{i}}{ }_{\beta}} \\
\mathrm{w}_{\mathrm{j}}=\frac{\mathrm{g}_{\mathrm{j} \alpha}}{\sum_{\mathrm{j}=1}^{\mathrm{n}} \mathrm{g}_{\mathrm{j} \alpha}}
\end{gathered}
$$

\subsection{Comprehensive Satisfaction in Multiple Situations}

This paper use comprehensive satisfaction integration functiont $(\cdot)$ and difference adjustment function $\varphi(\cdot)$ to react the difference between unilateral satisfactions within each other in this part. The sum of $\tau(\cdot)$ and $\varphi(\cdot)$ is comprehensive satisfaction of $\mu\left(A_{i}^{\delta_{i}}, B_{j}\right)$, write as $\sigma_{i}^{\delta_{i}}$, then get the comprehensive satisfaction matrix $\Theta . \tau(\cdot)$ is a strictly increasing function, which increases with two sides' unilateral matching satisfaction. $\varphi(\cdot)$ is a decreasing function, and it change with the absolute difference of unilateral satisfaction between two sides.

In the hierarchical treatment system, there are four possible scenarios:

Scenario 1. Superior hospitals have an overwhelming influence on matching

The comprehensive satisfaction mainly decided by superior hospitals.

$$
\begin{gathered}
\tau(\cdot)^{(a)}=\alpha_{i j}^{\delta_{i} w_{i}^{\delta_{i}}}, \varphi(\cdot)^{(a)}=\left|\alpha_{i}^{\delta_{i}}-\beta_{i}^{\delta_{i}}\right|^{-\left(w_{i}^{\delta_{i}}\right)} \\
\sigma_{i j}^{\delta_{i}(a)}=\alpha_{i}^{\delta_{i}} w_{i}^{\delta_{i}}+\left|\alpha_{i}^{\delta_{i}}-\beta_{i}^{\delta_{j}}\right|^{-\left(w_{i}^{\delta_{i}}\right)}
\end{gathered}
$$

Scenario 2. Subordinate hospitals have an overwhelming influence on matching

The comprehensive satisfaction mainly decided by subordinate hospitals.

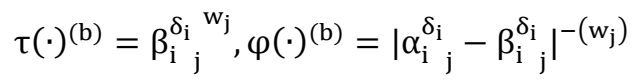

$$
\begin{aligned}
& \sigma_{i j}^{\delta_{i}(b)}=\beta_{i j}^{\delta_{i} w_{j}}+\left|\alpha_{i j}^{\delta_{i}}-\beta_{i}^{\delta_{j}}\right|^{-\left(w_{j}\right)}
\end{aligned}
$$

Scenario 3. Initiate a partnership

The comprehensive satisfaction is synthesized by bilateral market.

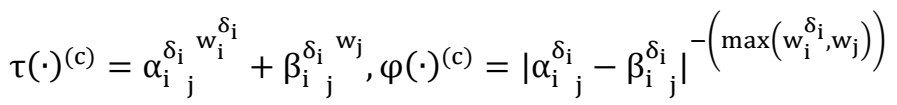

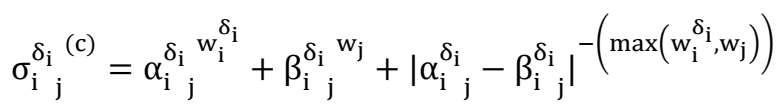

Scenario 4. Relationship is stable and balanced

The comprehensive satisfaction is obtained by means of balanced coordination.

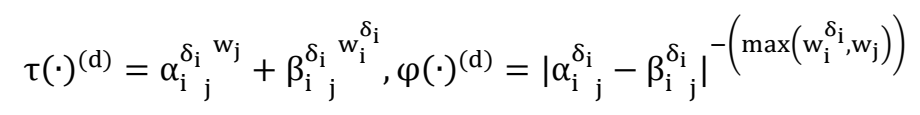

$\sigma_{i j}^{\delta_{i}(d)}=\alpha_{i j}^{\delta_{i} w_{j}}+\beta_{i j}^{\delta_{i} w_{i}^{\delta_{i}}}+\left|\alpha_{i j}^{\delta_{i}}-\beta_{i j}^{\delta_{i}}\right|^{-\left(\max \left(w_{i}^{\delta_{i}}, w_{j}\right)\right)}$

In the above four scenarios, the comprehensive satisfaction matrix $\Theta$ will be normalize to obtain the weight matrix $\mathrm{W}$, and $w_{i}^{\delta_{i}}$ is the weight of $A_{i}^{\delta_{i}}$ and $B_{j}$ matching pair in the bipartite graph, the formula is:

$$
w_{i}^{\delta_{i}}=\sigma_{i}^{\delta_{i}} / \max _{i, \delta_{i}, j} \sigma_{i j}^{\delta_{i}} i \in I ; 1 \leq \delta_{i} \leq s_{i} ; j \in J
$$

\section{Algorithm}

\subsection{Solving Methods}

Based on definition 1-4, the stable matching constraint can be obtained. Optimize target, and the optimization target is the maximum total number of matching bimodal, the optimization model is as follows:

$$
\max \mathrm{Z}=\sum_{\mathrm{i}=1}^{\mathrm{m}} \sum_{\delta_{\mathrm{i}}=1}^{\mathrm{s}_{\mathrm{i}}} \sum_{\mathrm{j}=1}^{\mathrm{n}} \sigma_{\mathrm{i} j \mathrm{j}}^{\delta_{\mathrm{i}}} \mathrm{x}_{\mathrm{i}}^{\delta_{\mathrm{i}}}
$$

s.t. 


$$
\begin{aligned}
& \sum_{j=1}^{n} x_{i}^{\delta_{i}}=1 i \in I, 1 \leq \delta_{i} \leq s_{i} \\
& \sum_{i=1}^{m} \sum_{\delta_{i}=1}^{s_{i}} x_{i}^{\delta_{i}} \leq 1 j \in J \\
& x_{i j}^{\delta_{i}}+\sum_{k: r_{i} \delta_{i} \leq r_{i j}^{\delta_{i}}} x_{i k}^{\delta_{i}}+\sum_{l: t_{l j} \leq t_{i}^{\delta_{j}}} x_{l j} \geq 1 ; i \in I, 1 \leq \delta_{i} \leq s_{i} ; j \in J \\
& \mathrm{x}_{\mathrm{i} j \mathrm{j}}^{\delta_{\mathrm{i}}}=0,1 \mathrm{i} \in \mathrm{I} ; 1 \leq \delta_{\mathrm{i}} \leq \mathrm{s}_{\mathrm{i}} ; \mathrm{j} \in \mathrm{J} \\
& \text { And } x_{i}^{\delta_{i}} \text { is a 0-1 variable, } x_{i}^{\delta_{i}}=\left\{\begin{array}{l}
1, A_{i}^{\delta_{i}}=\mu\left(B_{j}\right) \\
0, A_{i}^{\delta_{i}} \neq \mu\left(B_{j}\right)
\end{array}\right. \text {. }
\end{aligned}
$$

In the model, the optimization result is the maximum matching of bipartite graph. The constraint (20) shows that any subject $A_{i}^{s_{i}}$ only can match with 1 subject in set $B$, constraint shows that any subject $B_{j}$ can only match with 1 subject in set $\widetilde{A}$. In Figure 1, all vertices of set $A$ is fully-saturated matching point, and only part of set B's are fully-saturated matching points. Eq. (20) is stable matching constraints, all columns and rows including $x_{i}^{\delta_{i}}{ }_{j}$, matching pair $\mu\left(A_{i}^{\delta_{i}}, B_{j}\right)$. In all the preference value of $A_{i}^{\delta_{i}}$ is better than $r_{i}{ }_{i}{ }_{j}$ and all the preference value of $B_{j}$ is better than $t_{i}^{\delta_{i}}{ }_{j}$, there must be at least one set of matching pair, so as to eliminate hinder matching pairs. The constraint (20) indicates whether any subject $A_{i}^{s_{i}}$ is connected to vertex of subject $B_{j}$, connected is 1 , not is 0 . The above is an integer programming model, which can be solved by LINGO software. If the problem is large, it can be solved by genetic algorithm.

\subsection{Decision making Steps}

Step 1. Get the preference order matrix based on preference value.

Step 2. Adding the virtual subject element to built $\tilde{A}$, and then converting the 1-n matching problem into the 1-1 matching problem.

Step 3. Get the unilateral satisfaction matrix, the entropy value, the difference coefficient and the influence weight according to the formulas 1 to 4 .

Step 4. Use the formula $15-19$ to calculate the comprehensive satisfaction, and get the ownership matrix.

Step 5. Establish model (20), solve and get the optimal matching scheme.

Step 6. Discuss the matching satisfaction in different modes.

\section{Case Study and Discussions}

\subsection{Case Study}

To test this approach, the information provided in the 7-day questionnaire conducted by 3 Tertiary Hospitals and 7 community hospitals in Changsha city, P. R. China. Tertiary Hospital is superior hospital, and a community hospital is subordinate hospital. Based on the survey data, daily arrivals in Tertiary Hospitals (average) are as high as 8043 persons; however, the daily arrivals in Community Hospitals are only 976 persons, as shown in Figures 2 and 3. In contrast to the above data, the average daily arrivals are quite different in terms of Tertiary Hospitals and Community Hospitals. Daily transfers from Community Hospital are illustrated in Figure 4, and daily accept transfers by Tertiary Hospital are showed in Figure 5. As there did not establish a strict and exclusive referral system within the 10 hospitals, the daily total turnover quantity is not equal to the number of transfer.

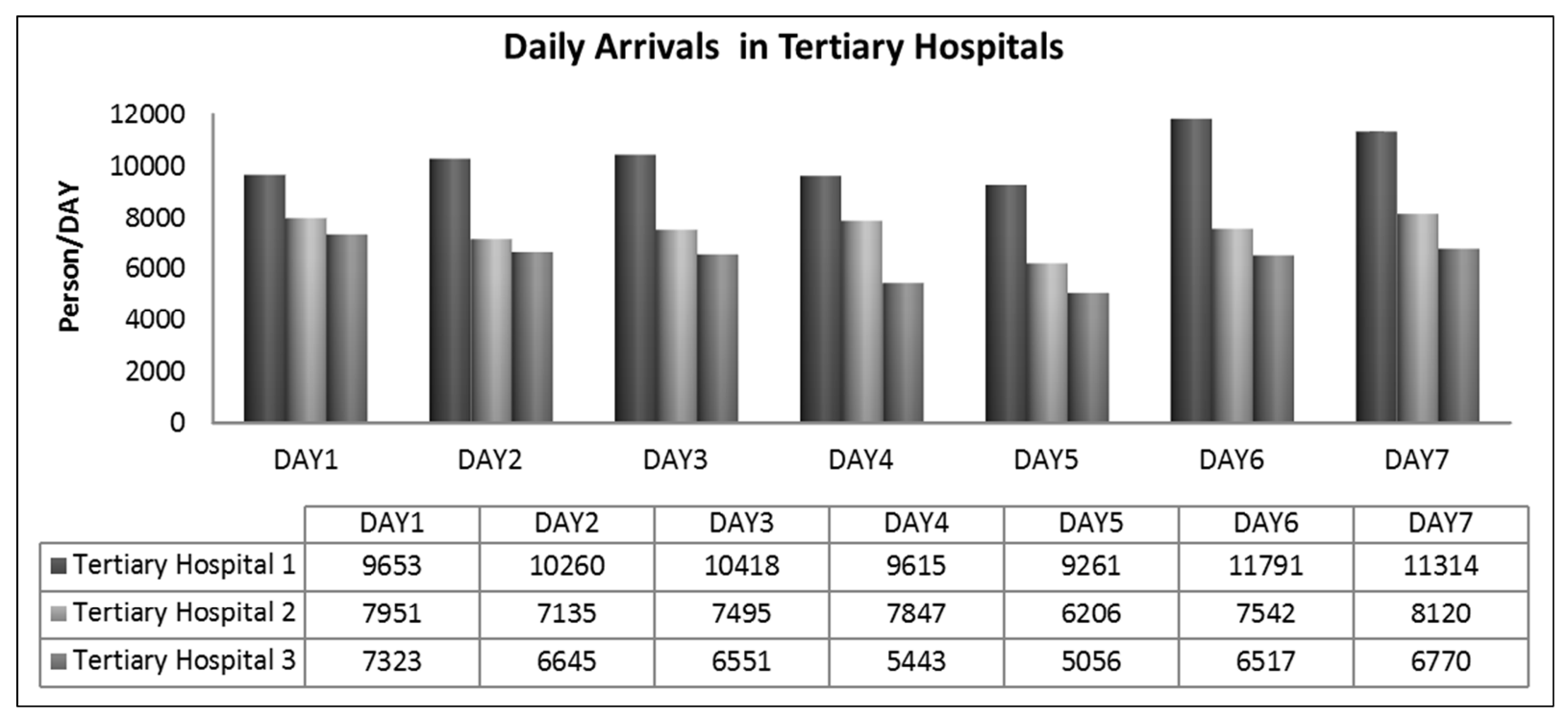

Figure 2. Daily Arrivals in Tertiary Hospitals. 


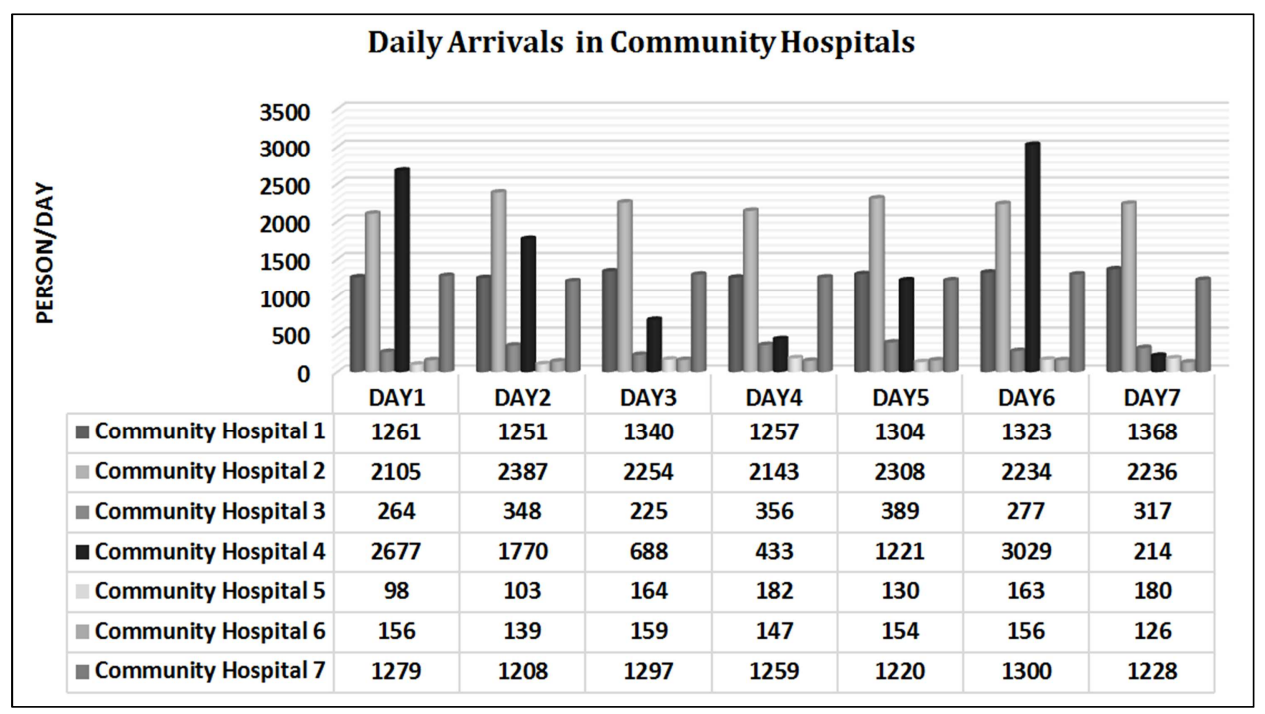

Figure 3. Daily Arrivals in Community Hospitals.

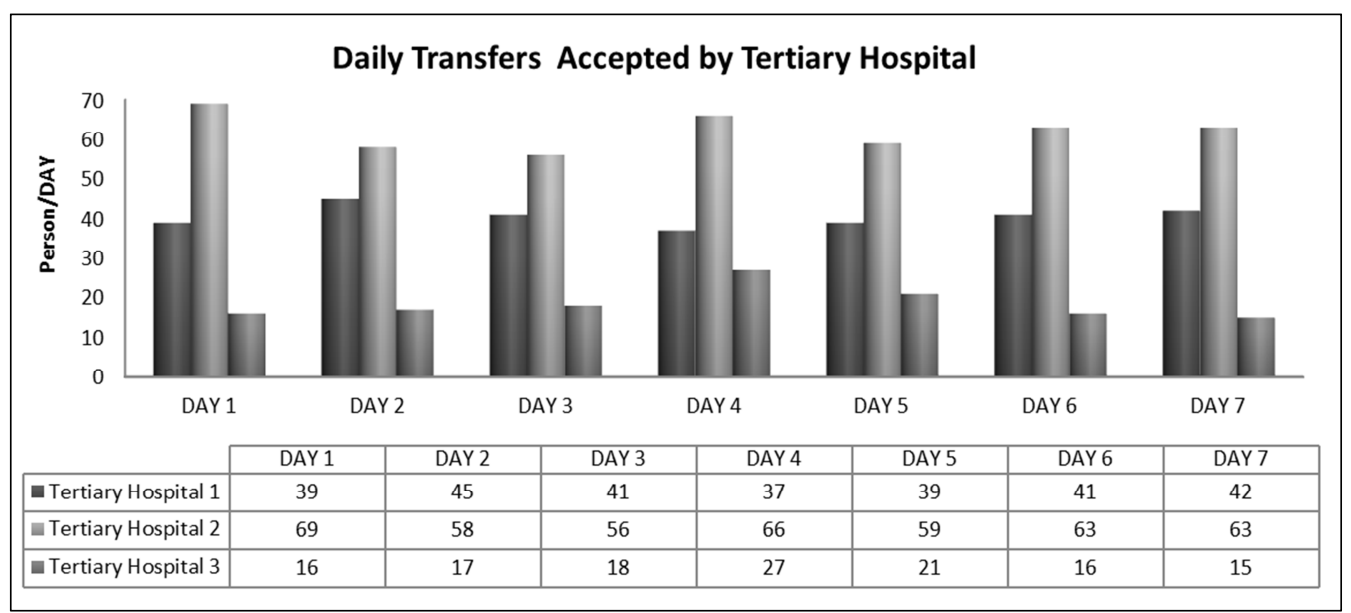

Figure 4. Daily Transfers Accepted by Tertiary Hospitals.

\begin{tabular}{|r|c|c|c|c|c|c|c|}
\hline \multicolumn{7}{|c|}{ Daily Transfers from Community Hospital } \\
\hline \\
\hline
\end{tabular}

Figure 5. Daily Transfers from Community Hospitals. 
To improve the using efficient of medical resources, the regional government has carry out hierarchical diagnosis and treatment cooperation. The hospitals are numbered as follows: tertiary hospitals $\left(A_{1}, A_{2}, A_{3}\right)$ and community hospitals $\left(B_{1}, B_{2}, B_{3}, B_{4}, B_{5}, B_{6}, B_{7}\right)$. The number of $B_{j}$ subjects can be accepted by $A_{i}$ is estimated by hospitals management experts and the numbers are assumed to be $2,3,1$.

To test and verify the advantage of stabilizing performance using this algorithm, the simulation calculation was compared with the stochastic matching algorithm, the strict matching method based on the partial preference information (abbreviated as "F-Y" algorithm) and the multi - scenario dynamic matching method proposed in this paper are adopted. Superior hospitals determine the order of subordinate hospitals in strict order as follows: medical data integrity, delivery timeliness, physical distance, medical data accuracy and other indicators, set strict order of subordinate hospitals as in Table 1. On the other hand, subordinate hospitals determine the strict order of superior hospitals in according to the following aspects: technical training, benefit distribution, physical distance, information system and other indicators, set it in Table 2.

Table 1. Strict order of subordinate hospitals.

\begin{tabular}{ll}
\hline Superior hospitals & Strict order \\
\hline$A_{1}$ & $B_{7}>B_{5}>B_{3}>B_{6}>B_{2}>B_{4}>B_{1}$ \\
$A_{2}$ & $B_{1}>B_{3}>B_{6}>B_{5}>B_{4}>B_{2}>B_{7}$ \\
$A_{3}$ & $B_{5}>B_{6}>B_{4}>B_{1}>B_{3}>B_{7}>B_{2}$ \\
\hline
\end{tabular}

Table 2. Strict order of superior hospitals.

\begin{tabular}{ll}
\hline Subordinate hospitals & Strict order \\
\hline$B_{1}$ & $A_{2}>A_{3}>A_{1}$ \\
$B_{2}$ & $A_{2}>A_{1}>A_{3}$ \\
$B_{3}$ & $A_{3}>A_{2}>A_{1}$ \\
$B_{4}$ & $A_{3}>A_{1}>A_{2}$ \\
$B_{5}$ & $A_{2}>A_{3}>A_{1}$ \\
$B_{6}$ & $A_{2}>A_{1}>A_{3}$ \\
$B_{7}$ & $A_{1}>A_{3}>A_{2}$ \\
\hline
\end{tabular}

Step 1. Get the preference order matrix based on preference value.

$$
\begin{aligned}
\mathrm{R} & =\left[\begin{array}{cccccccc} 
& \mathrm{B}_{1} & \mathrm{~B}_{2} & \mathrm{~B}_{3} & \mathrm{~B}_{4} & \mathrm{~B}_{5} & \mathrm{~B}_{6} & \mathrm{~B}_{7} \\
\mathrm{~A}_{1} & 7 & 5 & 3 & 6 & 2 & 4 & 1 \\
\mathrm{~A}_{2} & 1 & 6 & 2 & 5 & 4 & 3 & 7 \\
\mathrm{~A}_{3} & 4 & 7 & 5 & 3 & 1 & 2 & 6
\end{array}\right] \\
\mathrm{T} & =\left[\begin{array}{cccccccc} 
& \mathrm{B}_{1} & \mathrm{~B}_{2} & \mathrm{~B}_{3} & \mathrm{~B}_{4} & \mathrm{~B}_{5} & \mathrm{~B}_{6} & \mathrm{~B}_{7} \\
\mathrm{~A}_{1} & 3 & 2 & 3 & 2 & 3 & 2 & 1 \\
\mathrm{~A}_{2} & 1 & 1 & 2 & 3 & 1 & 1 & 3 \\
\mathrm{~A}_{3} & 2 & 3 & 1 & 1 & 2 & 3 & 2
\end{array}\right]
\end{aligned}
$$

Step 2. Adding the virtual subject element to built $\tilde{A}$, and then converting the 1-n matching problem into the 1-1 matching problem. Considering the degree of preference change in superior hospitals and subordinate hospitals, let $\varepsilon_{A}=0.6, \varepsilon_{B}=0.5$, and obtain the unilateral satisfaction matrix $\mathrm{A}$ and $\mathrm{B}$.

$$
\tilde{A}=\left[A_{1}^{1}, A_{1}^{2}, A_{2}^{1}, A_{2}^{2}, A_{2}^{3}, A_{3}^{1}\right]
$$

$$
\begin{gathered}
A=\left[\alpha_{i}{ }_{i}{ }_{j}\right]_{6 \times 7}=\left[\begin{array}{lllllll}
0.41 & 0.47 & 0.59 & 0.44 & 0.72 & 0.52 & 1.05 \\
0.41 & 0.47 & 0.59 & 0.44 & 0.72 & 0.52 & 1.05 \\
1.05 & 0.44 & 0.72 & 0.47 & 0.52 & 0.59 & 0.41 \\
1.05 & 0.44 & 0.72 & 0.47 & 0.52 & 0.59 & 0.41 \\
1.05 & 0.44 & 0.72 & 0.47 & 0.52 & 0.59 & 0.41 \\
0.52 & 0.41 & 0.47 & 0.59 & 1.05 & 0.72 & 0.44
\end{array}\right] \\
B=\left[\beta_{i}^{\delta_{i}}\right]_{6 \times 7}=\left[\begin{array}{lllllll}
0.64 & 0.76 & 0.64 & 0.76 & 0.64 & 0.76 & 1.04 \\
0.64 & 0.76 & 0.64 & 0.76 & 0.64 & 0.76 & 1.04 \\
1.04 & 1.04 & 0.76 & 0.64 & 1.04 & 1.04 & 0.64 \\
1.04 & 1.04 & 0.76 & 0.64 & 1.04 & 1.04 & 0.64 \\
1.04 & 1.04 & 0.76 & 0.64 & 1.04 & 1.04 & 0.64 \\
0.76 & 0.64 & 1.04 & 1.04 & 0.76 & 0.64 & 0.76
\end{array}\right]
\end{gathered}
$$

Step 3. Get the unilateral satisfaction matrix, the entropy value, the difference coefficient and the influence weight according to the formulas 1 to 4 .

$$
\begin{gathered}
e_{1 \beta}^{1}=e_{1 \beta}^{2}=0.9925, e_{2 \beta}^{1}=e_{2 \beta}^{2}=e_{2 \beta}^{3}=0.9887, e_{3 \beta}^{1}=0.9906 \\
g_{1 \beta}^{1}=g_{1 \beta}^{2}=0.0075, g_{2 \beta}^{1}=g_{2 \beta}^{2}=g_{2 \beta}^{3}=0.0113, g_{3 \beta}^{1}=0.0094 ; \\
w_{1 \beta}^{1}=w_{1 \beta}^{2}=0.1280, w_{2 \beta}^{1}=w_{2 \beta}^{2}=w_{2 \beta}^{3}=0.1940, w_{3 \beta}^{1}=0.1619 \\
e_{1 \alpha}=0.9780, e_{2 \alpha}=0.7938, e_{3 \alpha}=0.9525, e_{4 \alpha}=0.8267 \\
e_{5 \alpha}=0.9636, e_{6 \alpha}=0.9196, e_{7 \alpha}=0.8985 \\
g_{1 \alpha}=0.0220, g_{2 \alpha}=0.2062, g_{3 \alpha}=0.0475, g_{4 \alpha}=0.1733 \\
g_{5 \alpha}=0.0361, g_{6 \alpha}=0.0804, g_{7 \alpha}=0.1015
\end{gathered}
$$




$$
\begin{gathered}
w_{1 \alpha}=0.0330, w_{2 \alpha}=0.3091, w_{3 \alpha}=0.0712, w_{4 \alpha}=0.2598, \\
w_{5 \alpha}=0.0542, w_{6 \alpha}=0.1205, w_{7 \alpha}=0.1522,
\end{gathered}
$$

Step 4. Use the formula 15-19 to calculate the comprehensive satisfaction and get the ownership matrix.

Scenario (a): Comprehensive satisfaction $\Theta^{(a)}=\left[\sigma_{i_{j}}^{\delta_{i}}\right]_{6 \times 7}^{(a)}$

$$
\Theta^{(a)}=\left[\sigma_{i}^{\delta_{i}}{ }^{(a)}\right]_{6 \times 7}=\left[\begin{array}{llllll}
2.1008 & 2.0805 & 2.41982 .0553 & 2.3231 & 2.11952 .7259 \\
2.1008 & 2.0805 & 2.41982 .0553 & 2.3231 & 2.11952 .7259 \\
3.3071 & 1.9550 & 2.8939 & 2.2809 & 2.0164 & 2.07442 .1767 \\
3.3071 & 1.9550 & 2.89392 .2809 & 2.0164 & 2.07442 .1767 \\
3.3071 & 1.9550 & 2.89392 .2809 & 2.0164 & 2.07442 .1767 \\
2.1575 & 2.1353 & 1.98142 .0582 & 2.2245 & 2.42612 .0749
\end{array}\right]
$$

Similarly, the comprehensive satisfaction matrix for scenario (b, c, d) can be obtained:

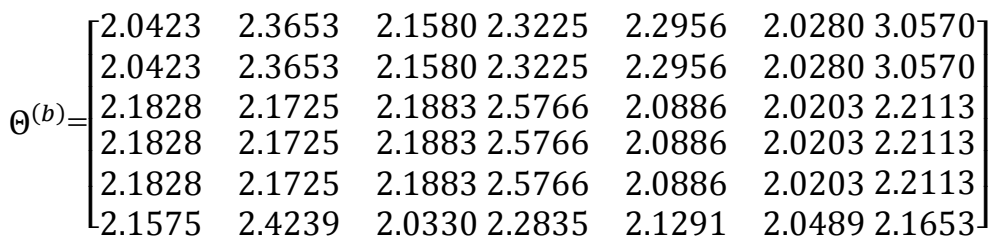

$$
\begin{aligned}
& \Theta^{(c)}=\left[\begin{array}{llllll}
3.0833 & 3.2736 & 3.39583 .2220 & 3.2689 & 3.1129 & 4.0632 \\
3.0833 & 3.2736 & 3.39583 .2220 & 3.2689 & 3.1129 & 4.0632 \\
4.3084 & 3.0227 & 3.87893 .4393 & 3.0206 & 3.0753 & 3.1033 \\
4.3084 & 3.0227 & 3.87893 .4393 & 3.0206 & 3.0753 & 3.1033 \\
4.3084 & 3.0227 & 3.87893 .4393 & 3.0206 & 3.0753 & 3.1033 \\
3.1466 & 3.2910 & 2.98323 .2029 & 3.1906 & 3.4154 & 3.0407
\end{array}\right] \\
& \Theta^{(d)}=\left[\begin{array}{llllll}
3.1179 & 3.2098 & 3.40073 .1482 & 3.2685 & 3.14954 .0637 \\
3.1179 & 3.2098 & 3.40073 .1482 & 3.2685 & 3.14954 .0637 \\
4.3063 & 2.9519 & 3.88463 .4165 & 3.1789 & 3.1662 & 3.1124 \\
4.3063 & 2.9519 & 3.88463 .4165 & 3.1789 & 3.1662 & 3.1124 \\
4.3063 & 2.9519 & 3.88463 .4165 & 3.1789 & 3.16623 .1124 \\
3.1883 & 3.2479 & 3.06093 .1342 & 3.1789 & 3.39903 .0368
\end{array}\right]
\end{aligned}
$$

Step 5. Establish model (7), solve and get the optimal matching scheme.

Step 6. Discuss the matching satisfaction in different modes.

\begin{tabular}{|c|c|c|c|c|}
\hline Results Algorithms & $\begin{array}{l}\text { Random matching } \\
\text { algorithm }\end{array}$ & $\begin{array}{l}\text { "F-Y" algorithm } \\
\left(w_{A}=1, w_{B}=0\right)\end{array}$ & $\begin{array}{l}\text { multi-scenarios dynamic matching } \\
\text { algorithm (without stability constraints) }\end{array}$ & $\begin{array}{l}\text { multi-scenarios dynamic matching } \\
\text { algorithm (with stability constraints) }\end{array}$ \\
\hline Matching & $\begin{array}{l}\left(\mathrm{A}_{1}^{1}, \mathrm{~B}_{1}\right) ;\left(\mathrm{A}_{1}^{2}, \mathrm{~B}_{7}\right) ; \\
\left(\mathrm{A}_{2}^{1}, \mathrm{~B}_{5}\right) ;\left(\mathrm{A}_{2}^{2}, \mathrm{~B}_{3}\right) \\
\left(\mathrm{A}_{2}^{3}, \mathrm{~B}_{2}\right) ;\left(\mathrm{A}_{3}^{1}, \mathrm{~B}_{6}\right) \\
\left(B_{4}, B_{4}\right)\end{array}$ & $\begin{array}{l}\left(A_{1}^{1}, B_{7}\right) ;\left(A_{1}^{2}, B_{2}\right) \\
\left(A_{2}^{1}, B_{3}\right) ;\left(A_{2}^{2}, B_{1}\right) \\
\left(A_{2}^{3}, B_{6}\right) ;\left(A_{3}^{1}, B_{5}\right) \\
\left(B_{4}, B_{4}\right)\end{array}$ & $\begin{array}{l}\left(A_{1}^{1}, B_{5}\right) ;\left(A_{1}^{2}, B_{7}\right) \\
\left(A_{2}^{1}, B_{4}\right) ;\left(A_{2}^{2}, B_{1}\right) \\
\left(A_{2}^{3}, B_{3}\right) ;\left(A_{3}^{1}, B_{6}\right) \\
\left(B_{2}, B_{2}\right)\end{array}$ & $\begin{array}{l}\left(A_{1}^{1}, B_{2}\right) ;\left(A_{1}^{2}, B_{7}\right) \\
\left(A_{2}^{1}, B_{1}\right) ;\left(A_{2}^{2}, B_{3}\right) \\
\left(A_{2}^{3}, B_{6}\right) ;\left(A_{3}^{1}, B_{5}\right) \\
\left(B_{4}, B_{4}\right)\end{array}$ \\
\hline Stable or not & No & Yes & No & Yes \\
\hline Total satisfaction & 14.1181 & 15.3063 & 15.9570 & 15.3063 \\
\hline
\end{tabular}

According to the comprehensive satisfaction matrix under different scenarios, establish model and solve it, and get the matching result of multi-scenarios dynamic matching algorithm. Similarly, according to the random matching algorithm and the "F-Y" algorithm can get the matching results. The above results are summarized, show in Table 3-6.

Table 3. Comparison the results of matching algorithms in Scenario (a).

Table 4. Comparison the results of matching algorithms in Scenario (b).

\begin{tabular}{lllll}
\hline Algorithms & $\begin{array}{l}\text { Random matching } \\
\text { algorithm }\end{array}$ & $\begin{array}{l}\text { "F-Y" algorithm } \\
\left(\boldsymbol{w}_{\boldsymbol{A}}=\mathbf{1}, \boldsymbol{w}_{\boldsymbol{B}}=\mathbf{0}\right)\end{array}$ & $\begin{array}{l}\text { multi-scenarios dynamic matching } \\
\text { algorithm (without stability constraints) }\end{array}$ & $\begin{array}{l}\text { multi-scenarios dynamic matching } \\
\text { algorithm }(\text { with stability constraints) }\end{array}$ \\
\hline & $\left(\mathrm{A}_{1}^{1}, \mathrm{~B}_{6}\right) ;\left(\mathrm{A}_{1}^{2}, \mathrm{~B}_{7}\right) ;$ & $\left(\mathrm{A}_{1}^{1}, \mathrm{~B}_{7}\right) ;\left(\mathrm{A}_{1}^{2}, \mathrm{~B}_{2}\right) ;$ & $\left(\mathrm{A}_{1}^{1}, \mathrm{~B}_{7}\right) ;\left(\mathrm{A}_{1}^{2}, \mathrm{~B}_{5}\right) ;$ & $\left(\mathrm{A}_{1}^{1}, \mathrm{~B}_{2}\right) ;\left(\mathrm{A}_{1}^{2}, \mathrm{~B}_{7}\right) ;$ \\
Matching & $\left(\mathrm{A}_{2}^{1}, \mathrm{~B}_{1}\right) ;\left(\mathrm{A}_{2}^{2}, \mathrm{~B}_{2}\right) ;$ & $\left(\mathrm{A}_{2}^{1}, \mathrm{~B}_{1}\right) ;\left(\mathrm{A}_{2}^{2}, \mathrm{~B}_{3}\right) ;$ & $\left(\mathrm{A}_{2}^{1}, \mathrm{~B}_{4}\right) ;\left(\mathrm{A}_{2}^{2}, \mathrm{~B}_{1}\right) ;$ & $\left(\mathrm{A}_{2}^{1}, \mathrm{~B}_{3}\right) ;\left(\mathrm{A}_{2}^{2}, \mathrm{~B}_{1}\right) ;$ \\
& $\left(\mathrm{A}_{2}^{3}, \mathrm{~B}_{3}\right) ;\left(\mathrm{A}_{3}^{1}, \mathrm{~B}_{4}\right)$ & $\left(\mathrm{A}_{2}^{3}, \mathrm{~B}_{6}\right) ;\left(\mathrm{A}_{3}^{1}, \mathrm{~B}_{5}\right)$ & $\left(\mathrm{A}_{2}^{3}, \mathrm{~B}_{3}\right) ;\left(\mathrm{A}_{3}^{1}, \mathrm{~B}_{2}\right) ;$ & $\left(\mathrm{A}_{2}^{3}, \mathrm{~B}_{6}\right) ;\left(\mathrm{A}_{3}^{1}, \mathrm{~B}_{5}\right) ;$ \\
& $\left(B_{5}, B_{5}\right)$ & $\left(B_{4}, B_{4}\right)$ & $\left(B_{6}, B_{6}\right)$ & $\left(\mathrm{B}_{4}\right)$ \\
Stable or not & No & Yes & No & Yes \\
Total satisfaction & 13.9122 & 13.9428 & 14.7242 & 13.9428 \\
\hline
\end{tabular}


Table 5. Comparison the results of matching algorithms in Scenario (c).

\begin{tabular}{|c|c|c|c|c|}
\hline Results Algorithms & $\begin{array}{l}\text { Random matching } \\
\text { algorithm }\end{array}$ & $\begin{array}{l}\text { "F-Y" algorithm } \\
\left(w_{A}=1, w_{B}=0\right)\end{array}$ & $\begin{array}{l}\text { multi-scenarios dynamic matching } \\
\text { algorithm (without stability constraints) }\end{array}$ & $\begin{array}{l}\text { multi-scenarios dynamic matching } \\
\text { algorithm (with stability constraints) }\end{array}$ \\
\hline Matching & $\begin{array}{l}\left(A_{1}^{1}, B_{3}\right) ;\left(A_{1}^{2}, B_{2}\right) \\
\left(A_{2}^{1}, B_{1}\right) ;\left(A_{2}^{2}, B_{6}\right) \\
\left(A_{2}^{3}, B_{5}\right) ;\left(A_{3}^{1}, B_{4}\right) \\
\left(B_{7}, B_{7}\right)\end{array}$ & $\begin{array}{l}\left(A_{1}^{1}, B_{7}\right) ;\left(A_{1}^{2}, B_{3}\right) \\
\left(A_{2}^{1}, B_{1}\right) ;\left(A_{2}^{2}, B_{2}\right) \\
\left(A_{2}^{3}, B_{6}\right) ;\left(A_{3}^{1}, B_{5}\right) \\
\left(B_{4}, B_{4}\right)\end{array}$ & $\begin{array}{l}\left(A_{1}^{1}, B_{2}\right) ;\left(A_{1}^{2}, B_{7}\right) ; \\
\left(A_{2}^{1}, B_{4}\right) ;\left(A_{2}^{2}, B_{1}\right) ; \\
\left(A_{2}^{3}, B_{3}\right) ;\left(A_{3}^{1}, B_{6}\right) ; \\
\left(B_{5}, B_{5}\right)\end{array}$ & $\begin{array}{l}\left(A_{1}^{1}, B_{2}\right) ;\left(A_{1}^{2}, B_{7}\right) \\
\left(A_{2}^{1}, B_{3}\right) ;\left(A_{2}^{2}, B_{1}\right) \\
\left(A_{2}^{3}, B_{6}\right) ;\left(A_{3}^{1}, B_{5}\right) \\
\left(B_{5}, B_{5}\right)\end{array}$ \\
\hline Stable or not & No & No & Yes & Yes \\
\hline Total satisfaction & 20.2765 & 21.0559 & 22.3788 & 21.7900 \\
\hline
\end{tabular}

Table 6. Comparison the results of matching algorithms in Scenario (d).

\begin{tabular}{|c|c|c|c|c|}
\hline Results & $\begin{array}{l}\text { Random matching } \\
\text { algorithm }\end{array}$ & $\begin{array}{l}\text { "F-Y" algorithm } \\
\left(w_{A}=1, w_{B}=0\right)\end{array}$ & $\begin{array}{l}\text { multi-scenarios dynamic matching } \\
\text { algorithm (without stability constraints) }\end{array}$ & $\begin{array}{l}\text { multi-scenarios dynamic matching } \\
\text { algorithm (with stability constraints) }\end{array}$ \\
\hline Matching & $\begin{array}{l}\left(A_{1}^{1}, B_{5}\right) ;\left(A_{1}^{2}, B_{7}\right) ; \\
\left(A_{2}^{1}, B_{1}\right) ;\left(A_{2}^{2}, B_{2}\right) ; \\
\left(A_{2}^{3}, B_{3}\right) ;\left(A_{3}^{1}, B_{4}\right) \\
\left(B_{6}, B_{6}\right)\end{array}$ & $\begin{array}{l}\left(A_{1}^{1}, B_{7}\right) ;\left(A_{1}^{2}, B_{3}\right) \\
\left(A_{2}^{1}, B_{1}\right) ;\left(A_{2}^{2}, B_{2}\right) \\
\left(A_{2}^{3}, B_{6}\right) ;\left(A_{3}^{1}, B_{5}\right) \\
\left(B_{4}, B_{4}\right)\end{array}$ & $\begin{array}{l}\left(\mathrm{A}_{1}^{1}, \mathrm{~B}_{5}\right) ;\left(\mathrm{A}_{1}^{2}, \mathrm{~B}_{7}\right) \\
\left(\mathrm{A}_{2}^{1}, \mathrm{~B}_{4}\right) ;\left(\mathrm{A}_{2}^{2}, \mathrm{~B}_{1}\right) \\
\left(\mathrm{A}_{2}^{3}, \mathrm{~B}_{3}\right) ;\left(\mathrm{A}_{3}^{1}, \mathrm{~B}_{6}\right) \\
\left(B_{2}, B_{2}\right)\end{array}$ & $\begin{array}{l}\left(A_{1}^{1}, B_{2}\right) ;\left(A_{1}^{2}, B_{7}\right) ; \\
\left(A_{2}^{1}, B_{3}\right) ;\left(A_{2}^{2}, B_{6}\right) ; \\
\left(A_{2}^{3}, B_{1}\right) ;\left(A_{3}^{1}, B_{5}\right) ; \\
\left(B_{4}, B_{4}\right)\end{array}$ \\
\hline Stable or not & No & No & No & Yes \\
\hline Total satisfaction & 21.6092 & 21.0678 & 22.3386 & 21.8095 \\
\hline
\end{tabular}

\subsection{Discussions}

In this section, the merits of the four algorithms was discussed firstly, and then discuss the possibility of applying multi-scenarios dynamic matching algorithm for regional medical resources matching management and address some practical problems that may arise when implementing the results. The multi-scenarios dynamic matching algorithm is general and efficient, can be applied to a wide range of Hierarchical Treatment Systems. Comparison the results about total satisfaction and stability of matching algorithms are showed in Figure 6 and Table 7.

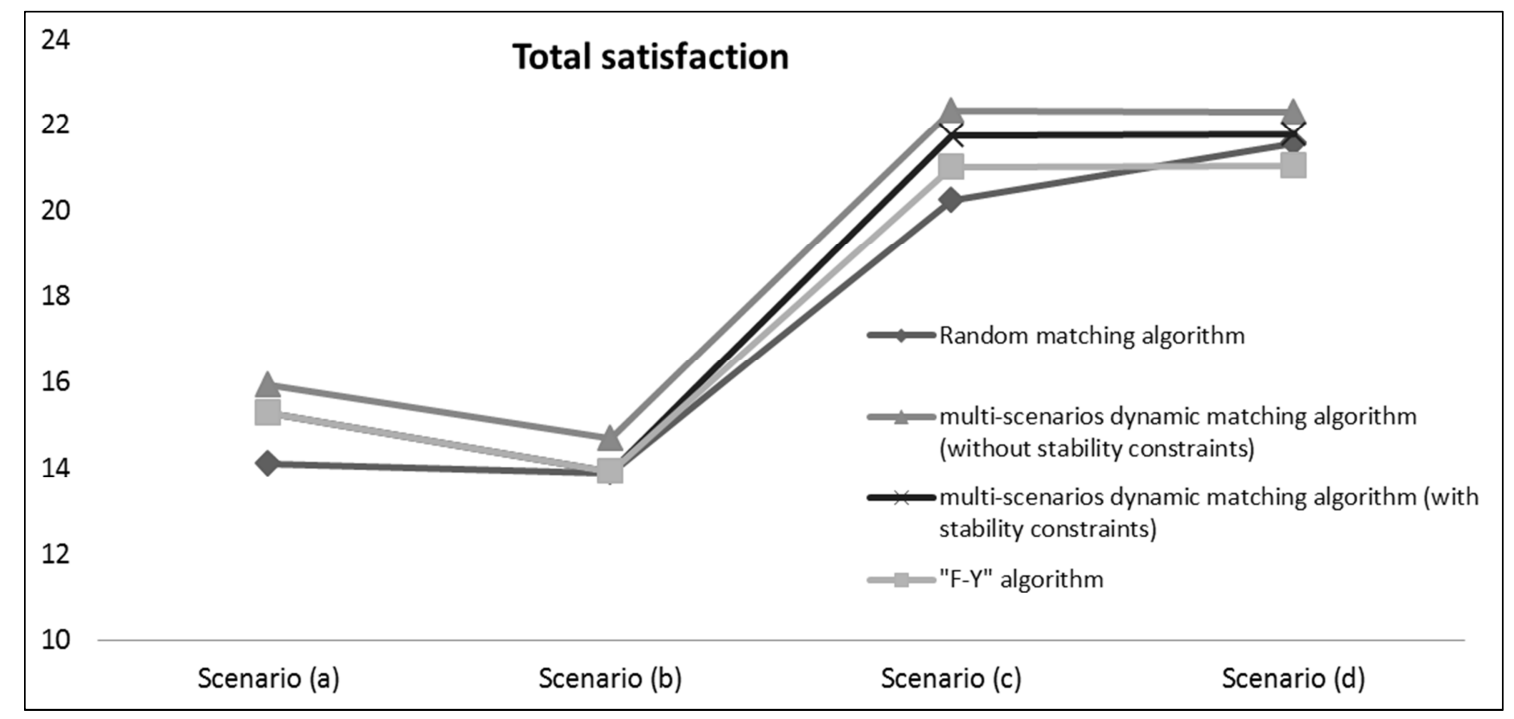

Figure 6. Comparison the results about total satisfaction.

Table 7. Comparison the results about stability.

\begin{tabular}{lllll}
\hline Stable or not & $\begin{array}{l}\text { Random matching } \\
\text { algorithm }\end{array}$ & $\begin{array}{l}\text { "F-Y" matching } \\
\text { algorithm }\end{array}$ & $\begin{array}{l}\text { multi-scenarios dynamic matching } \\
\text { algorithm (without stability constraints) }\end{array}$ & $\begin{array}{l}\text { multi-scenarios dynamic matching } \\
\text { algorithm (with stability constraints) }\end{array}$ \\
\hline Scenario (a) & No & Yes & No & Yes \\
Scenario (b) & No & Yes & No & Yes \\
Scenario (c) & No & No & Yes & Yes \\
Scenario (d) & No & No & No & Yes \\
\hline
\end{tabular}

To solve the problem of medical resource matching in Hierarchical Treatment Systems, the result of the random matching algorithm is the worst: total satisfaction is often the lowest (14.1181, 13.9122, 20.2765, and 21.6092), and there exists $\mu$ - hinder matching pair leading to unstable matching. Therefore, the solution to this problem must be optimized by scientific management methods, and this is why this problem is worth researching.

Scenario (A) and (b) all are easy scenarios, and the results of "F-Y" matching algorithm are the same as the algorithm in these two scenarios. However, in complex scenarios (c) and (d), linear weighting is used to transform the multi-objective 
problem into a single objective scheme in "F-Y" matching algorithm. The result is that it will be unsolvable if add a stable constraint, on the other way, there will exist $\mu$ - Hinder matching pair when it removes the stability constraint.

Multi-scenarios dynamic matching algorithm for hierarchical treatment system presented in this article is a possible idea of innovation. It takes the power-balance into consider between superior hospitals and subordinate hospitals in different scenarios, get a dynamic balance results, more in line with the reality, is feasible. In addition, this algorithm is analyzed from two situations: without stability constraints and with stability constraints. In all four scenarios, the results show that the total matching satisfaction value is higher when there without stability constraints. These results also prove that the stability constraint will sacrifice the unilateral satisfaction of some subjects. Stability is the result of multiple compromises.

The feasibility of different scenarios and dynamic balance resulting are the major practical considerations. In fact, to implement the results of this approach, the relative strength between superior hospitals and subordinate hospitals was required to determine. This concerns the government regulation, hospital quantity in two types, benefits distribution and other factors in practice. In addition, the strict orders of each other are also necessary, and these can be obtained by a questionnaire survey. Hence, only is required to sort the preference data as the input, and use this algorithm to develop heuristic optimization program, hospitals can get a stable and optimal matching program. If a reasonable solution cannot be finding, then need to re-investigate the preference sequence data.

The actual problems that may emerge at this stage include changes in referral methods, dynamic changes of admission capacity in superior hospitals and subordinate hospitals, and other uncertainties. Each of these has to be determined according to local conditions. However, experience has shown that flexibility is usually present when the benefits of change are emphasized.

This algorithm does not consider uncertainty and contingencies that is, uncertainty about acceptable capacity and other elements in the model. In addition, this paper set the admission number of superior hospitals based on projected load, rather than adaptively responding to the observed load.

\section{Conclusions}

This paper showed a Multi-scenarios dynamic matching algorithm for hierarchical treatment system by modifying comprehensive satisfaction integration function and differential adjustment function. This paper concentrated on the stability and total satisfaction goals of system matching.

The proposed multi-scenarios dynamic matching algorithm is suitable for referral matching in different situations. Based on the unilateral satisfaction, comprehensive satisfaction of both sides, and stability constraints, the 1-n matching model of multi-scenarios is constructed, and the matching scheme will be obtained after the model is solved. Compare with the random matching algorithm and "F-Y" matching algorithm (improved GS algorithm), this method is intuitive and adaptable, and can be used in Multi-scenarios, the total comprehensive satisfaction is scientifically, it is worth mentioning that the stability of multi-scenarios dynamic matching algorithm (with stability constraints) is the best one. The simulation results show that the algorithm proposed in this paper is more practical.

This method serves as a decision-making reference for the bilateral matching encountered in the problem of "hierarchical treatment system" around the world. However, most of the participants in a hierarchical treatment system are limited rational and incomplete information owner, their decision is not entirely rational but has a certain degree of randomness. In addition, the uncertainty of the system environment and individual capacity is also challenging the management mechanism. These are important directions for future research.

\section{Conflict of Interest}

All the authors do not have any possible conflicts of interest.

\section{Acknowledgements}

This work was supported by NSFC (National Natural Science Foundation of China) [grant number 71601043, 71671039, 71671040] and 2017 Youth Innovation Driven Project in Hunan University of Commerce [grant number 17QD06] .

\section{References}

[1] Dietl, H., M. Lang, and P. L. Lin, Advertising pricing models in media markets: Lump-sum versus per-consumer charges. Information Economics and Policy, 2013. 25 (4): p. 257-271.

[2] Fleiner, T., R. W. Irving, and D. F. Manlove, An algorithm for a super-stable roommates problem. Theoretical Computer Science, 2011. 412 (50): p. 7059-7065.

[3] Gale, D. and L. S. Shapley, College Admissions and the Stability of Marriage. American Mathematical Monthly, 2013. 120 (5): p. 386-391.

[4] Ingolfsson, A., et al., Combining integer programming and the randomization method to schedule employees. European Journal of Operational Research, 2010. 202 (1): p. 153-163.

[5] Rochet, J. C. and J. Tirole, Tying in two-sided markets and the honor all cards rule. International Journal of Industrial Organization, 2008. 26 (6): p. 1333-1347.

[6] Boudreau, J. W. and V. Knoblauch, What price stability? Social welfare in matching markets. Mathematical Social Sciences, 2014. 67: p. 27-33.

[7] Feldman, Z., et al., Staffing of time-varying queues to achieve time-stable performance. Management Science, 2008. 54 (2): $\mathrm{p}$. $\mathrm{V}-\mathrm{V}$. 
[8] Sulzle, K., Duopolistic competition between independent and collaborative business-to-business marketplaces. International Journal of Industrial Organization, 2009. 27 (5): p. 615-624.

[9] Coles, P. and R. Shorrer, Optimal truncation in matching markets. Games and Economic Behavior, 2014. 87: p. 591-615.

[10] Fletcher, A., et al., The DH Accident and Emergency Department model: a national generic model used locally. Journal of the Operational Research Society, 2007. 58 (12): p. $1554-1562$

[11] Drgas-Burchardt, E. and Z. Switalski, A number of stable matchings in models of the Gale-Shapley type. Discrete Applied Mathematics, 2013. 161 (18): p. 2932-2936.

[12] Ashlagi, I., et al., Nonsimultaneous Chains and Dominos in Kidney- Paired Donation-Revisited. American Journal of Transplantation, 2011. 11 (5): p. 984-994.

[13] Sarne, D. and S. Kraus, Managing parallel inquiries in agents' two-sided search. Artificial Intelligence, 2008. 172 (4-5): p. 541-569.

[14] Munro, J., S. Mason, and J. Nicholl, Effectiveness of measures to reduce emergency department waiting times: a natural experiment. Emergency Medicine Journal, 2006. 23 (1): p. 35-39.

[15] Roth, A. E., COMMON AND CONFLICTING INTERESTS IN 2-SIDED MATCHING MARKETS. European Economic Review, 1985. 27 (1): p. 75-96.

[16] Roth, A. E., T. Sonmez, and M. U. Unver, Kidney paired donation with compatible pairs. American Journal of Transplantation, 2008. 8 (2): p. 463-463.
[17] Roth, A. E., et al., Utilizing list exchange and nondirected donation through 'Chain' paired kidney donations. American Journal of Transplantation, 2006. 6 (11): p. 2694-2705.

[18] Vasconcelos, H., Is exclusionary pricing anticompetitive in two-sided markets? International Journal of Industrial Organization, 2015. 40: p. 1-10.

[19] Chakraborty, A., A. Citanna, and M. Ostrovsky, Two-sided matching with interdependent values. Journal of Economic Theory, 2010. 145 (1): p. 85-105.

[20] Ashlagi, I. and F. Klijn, Manipulability in matching markets: conflict and coincidence of interests. Social Choice and Welfare, 2012. 39 (1): p. 23-33.

[21] Izady, N. and D. Worthington, Setting staffing requirements for time dependent queueing networks: The case of accident and emergency departments. European Journal of Operational Research, 2012. 219 (3): p. 531-540.

[22] Leider, S. and A. E. Roth, Kidneys for Sale: Who Disapproves, and Why? American Journal of Transplantation, 2010. 10 (5): $\mathrm{p}$ 1221-1227.

[23] Klumpp, T., Two-sided matching with spatially differentiated agents. Journal of Mathematical Economics, 2009. 45 (5-6): p. 376-390.

[24] Ronn, E., NP-COMPLETE STABLE MATCHING PROBLEMS. Journal of Algorithms, 1990. 11 (2): p. 285-304.

[25] Rees, M. A., et al., Global kidney exchange: Financially incompatible pairs are not transplantable compatible pairs. American Journal of Transplantation, 2017. 17 (10): p. 2743-2744. 